\title{
Destinos Turísticos Inteligentes: o caso de Curitiba/PR (Brasil)
}

\section{Smart Tourist Destinations: the case of Curitiba/PR (Brazil)}

\author{
Mateus José Alves Pinto (PINTO, M. J. A.) ${ }^{*}$
}

\begin{abstract}
RESUMO - O fenômeno dos destinos turísticos inteligentes é recente e a sua conceituação ainda está em processo. É certo que a ideia do destino inteligente nasceu da noção de cidade inteligente. Deste modo, no presente trabalho se teve o objetivo de analisar se Curitiba estava se tornando um destino turístico inteligente tomando-se como base o ano de 2016. A metodologia da pesquisa foi exploratória, porque visou proporcionar maior familiaridade com o tema; bibliográfica e documental; e qualitativa, pois se estudou um fenômeno social. A coleta de dados ocorreu em duas etapas: o levantamento bibliográfico e o levantamento documental, em que foram analisados o Plano Municipal de Turismo (2015), o Plano Diretor de Curitiba (2015), notícias e reportagens para identificar projetos e ações que estavam sendo realizados em Curitiba e que a caracterizassem como um destino turístico inteligente. Os resultados da pesquisa evidenciaram que Curitiba ainda não era um destino turístico inteligente, porque precisaria desenvolver melhor alguns quesitos como tecnologia e mobilidade.
\end{abstract}

Palavras-chave: Turismo; Destinos Turísticos Inteligentes; Cidades Inteligentes; Curitiba; Inovação; Tecnologia; Sustentabilidade; Acessibilidade.

ABSTRACT - The phenomenon of smart tourist destinations is recent and its conceptualization is still in process. It is known that the idea of smart destination was born from the notion of smart city. That way, this paper aimed to analyze if Curitiba was becoming a smart tourist destination based on the year 2016. The research methodology was exploratory, because it aimed to provide greater familiarity with the theme; bibliographic and documental; and qualitative, because it studied a social phenomenon. The data collection happened in two phases: the bibliographic survey and the documental survey, where it was analyzed the Municipal Tourism Plan (2015), the Director Plan of Curitiba (2015), news and reports to identify projects and actions that Curitiba was executing and that characterizes it as a smart tourist destination. The research results showed that Curitiba was not yet a smart tourist destination, because the city would need to better develop some areas like technology and mobility.

Key Words: Tourism; Smart Tourist Destinations; Smart Cities; Curitiba; Innovation; Technology; Sustainability; Accessibility.

\footnotetext{
* Formação: Bacharel em Turismo pela Universidade Federal do Paraná (UFPR). Atividade profissional: Consultor educacional na YES - Young Education Studies. Endereço físico para correspondência: Rua Dom Manuel da Silveira Delboux, n. 137, Tarumã. CEP: 82.800-160 - Curitiba - Paraná - Brasil. E-mail: mateus401@hotmail.com
} 


\section{INTRODUÇÃO}

Neste artigo se apresentam os resultados alcançados nos levantamentos bibliográfico e documental realizados pelo autor em seu trabalho de conclusão de curso (TCC), defendido no ano de 2016 a fim de se obter o título de bacharel em turismo pela Universidade Federal do Paraná.

Levou-se em conta que as cidades estão passando por uma evolução, que se acelerou no século XXI, marcada pelo advento da internet 2.0, o aumento da conectividade e interatividade entre as sociedades, o surgimento de novas ferramentas de computação e de coleta de dados, impulsionando assim a economia e o conhecimento participativo. (SEGITTUR, 2015).

Neste cenário de constante inovação é que surgem as cidades inteligentes que, segundo Caragliu, Del Bo e Nijkamp (2011), são aquelas que aliam investimentos no capital humano, em infraestrutura de comunicação modernas (TICs) e em infraestruturas tradicionais (exemplo: meios de transportes) para estimular $\mathrm{o}$ crescimento econômico e sustentável dos centros urbanos.

Levando em consideração este contexto, e tendo a experiência das cidades inteligentes como referencial, é necessário implementar um novo modelo de território turístico: o destino turístico inteligente (DTI). (SEGITTUR, 2015). Segundo López de Ávila e García (2013, p. 60, tradução livre), este novo espaço é “inovador, consolidado sobre a base do território e de uma infraestrutura tecnológica de vanguarda, que une os conceitos de sustentabilidade, conhecimento e inovação tecnológica.”.

No ano de 2017 Curitiba foi o palco, pelo terceiro ano consecutivo, de um dos maiores eventos globais sobre cidades inteligentes, o Smart City Business America Congress \& Expo. Juntamente com outras ações de inovação, como a inclusão da cidade na Rede de Cidades Criativas da Organização das Nações Unidas para a Educação, a Ciência e a Cultura - UNESCO (RUIZ, 2015), Curitiba passou a ganhar cada vez mais espaço no grupo das cidades consideradas inteligentes.

Como uma cidade inteligente e um dos principais destinos indutores do turismo brasileiro (MTUR; SEBRAE; FGV, 2015), Curitiba também poderia se tornar um destino inteligente, usando os seus recursos tecnológicos disponíveis para permitir que a sua demanda e oferta turística cocriassem valor, prazer e experiências para o turista, 
gerando benefícios para as organizações e para a cidade. (BOES; BUHALIS; INVERSINI, 2015).

Uma pesquisa é um processo sequencial de busca por esclarecimentos para uma pergunta prévia, cuja resposta é de interesse da comunidade científica. (FILHO; FILHO, 2013; GIL, 2010). Portanto, para melhor entender a temática desse trabalho definiu-se como problema da pesquisa: Curitiba, como uma cidade inteligente, poderia também se tornar um destino turístico inteligente?.

Nesse contexto, o presente trabalho teve como objetivo analisar se Curitiba estava se tornando um destino turístico inteligente. Como desdobramentos, definiu-se como objetivos específicos: a) analisar as ações e projetos desenvolvidos na cidade que a enquadrassem como uma cidade inteligente e como um destino turístico inteligente, de acordo com a base teórico-conceitual dos temas; b) analisar se o Plano Municipal de Turismo de Curitiba (2015) e o Plano Diretor (2015) possuíam aderência com os ideais das cidades inteligentes e dos destinos turísticos inteligentes; e c) utilizar a metodologia da "Sociedad Estatal para la Gestión de la Innovación y las Tecnologías Turísticas, S.A.” (SEGITTUR - Espanha) para analisar Curitiba como um destino turístico inteligente.

Após a introdução apresentada, para melhor desenvolvimento deste trabalho, seguem as revisões de literatura sobre destinos turísticos, cidades inteligentes e destinos turísticos inteligentes; a metodologia; a análise dos resultados; e as considerações finais.

\section{DESTINOS TURÍSTICOS}

O turismo não é um fenômeno de hoje e seu início perde-se na memória do tempo. (SANTOS, 2013). Desta maneira, ele vem sendo estudado e pesquisado segunda a ótica de diversas áreas do conhecimento, caracterizando-se assim como uma atividade sistêmica e complexa. (LOTZ, 2002).

Percebe-se a complexidade do turismo, quando se analisam os diversos agentes e estruturas que estão envolvidos na sua operacionalização como, por exemplo: atores públicos e privados; recursos naturais e culturais; as estruturas básicas de apoio para a viagem acontecer, entre outros. (THOMAZ, 2014; VIGNATI, 2008). 
Os destinos turísticos fazem parte desta cadeia multifacetada e recebem influências constantes destes agentes. Em vista disso, é fundamental entender como eles são trabalhados na literatura. Segundo Ruiz (2015), enquanto alguns autores associam o conceito de destino turístico a uma abordagem geográfica, outros pesquisadores utilizam mais relações mercadológicas, onde o destino turístico deve ser trabalhado como um produto para ser comercializado.

Nos estudos da Geografia, o destino turístico é apresentado como uma área com limites físicos definidos (RUIZ, 2015), como afirmam Moletta e Garcia (2000, p. 9) quando escrevem que o destino "é a localidade, região ou até mesmo um país que o turista escolheu para passar as suas próximas férias.”. Valls (2006, p. 15) vai além, ao constatar que o "destino turístico pode se associar a qualquer unidade territorial que tenha vocação de planejamento e possa dispor de certa capacidade administrativa para desenvolvê-la.".

Por sua vez, Santos (2013, p. 54) afirma que "a região, a área ou o espaço definido como destino, para a Geografia, não perde a sua dimensão espacial humana.”. Ele continua o seu entendimento, afirmando que o destino "é também um espaço fundamental à vida dos homens e onde ocorrem as sensibilizações e sociabilidades dos sujeitos.”. (SANTOS, 2013, p. 54).

Deste modo, é possível compreender que os destinos turísticos são mais do que apenas delimitações geográficas e devem englobar as funções sociais, culturais, políticas, ambientais e econômicas que a atividade turística possui. (VIGNATI, 2008).

Os autores Saraniemi e Kylanen (2011), por exemplo, apresentam uma abordagem mais comercial que entende o espaço do destino turístico na esfera física e até mesmo virtual, onde transações e atividades mercadologicamente orientadas ocorrem, modificando a relação entre a produção e o consumo. Knop e Machado (2017) reforçam esta ideia do destino no espaço virtual quando afirmam que os operadores turísticos, consumidores potenciais, produtores e viajantes estão utilizando ativamente as redes sociais e as novas tecnologias para vender, consumir, avaliar e criticar os produtos e serviços turísticos.

Com um enfoque no próprio turismo, Cooper et al. (2001, p. 136) definem o destino como sendo a concentração "de instalações e serviços projetados para atender às necessidades do turista.”. Para os autores, é nele que se encontram as atrações e os 
serviços de apoio que o visitante necessita e, por isso, é o elemento mais significativo do sistema turístico, fornecendo o foco para a análise dos fluxos e do impacto da atividade. (COOPER et al., 2001).

\section{CIDADES INTELIGENTES}

Por milhares de anos, as sociedades migraram para as cidades para se conectar, criar novas ideias, encontrar trabalho e gerar riquezas, devido ao fato de que estes locais permitem que o ser humano produza mais com menos espaço e tempo. (TOWNSEND, 2013). McLaren e Agyeman (2015, p. 2, tradução livre) atrevem-se em afirmar que "as cidades podem ser a melhor forma de organização que a nossa espécie consegue alcançar.".

As cidades ocupam apenas $2 \%$ da superfície terrestre. Todavia, aproximadamente $51 \%$ da população mundial habita nestas áreas urbanas, consumindo dois terços da energia nacional, 60\% dos recursos hídricos e produzindo $70 \%$ dos gases responsáveis pelo efeito estufa. (AENOR, 2014; BASTOS, 2015; SHARK, 2014).

Os efeitos negativos causados pela rápida expansão da urbanização, como, por exemplo, a má gestão e distribuição de recursos, o grande número de pessoas vivendo na extrema pobreza, o trânsito, a poluição, a perda de biodiversidade, entre outros (BASTOS, 2015; MCLAREN; AGYEMAN, 2015), acabaram "levando as autoridades governamentais, bem como várias instituições filantrópicas privadas, a idealizarem diversos projetos de intervenção sobre o espaço urbano.”. (OLIVEIRA, 2000, p. 17).

Deste modo, com o propósito de empregar as novas tecnologias existentes para resolver ou minimizar os problemas das cidades modernas, aumentando a atração de empresas, criação de empregos, turismo e qualidade de vida dos habitantes, é que nascem as cidades inteligentes. (BASTOS, 2015).

A definição clássica de uma cidade inteligente envolve a ascensão da tecnologia de informação e comunicação (TIC). Segundo Stimmel (2015), o termo "cidade inteligente" define um novo ambiente, que é desenhado para melhorar a performance urbana através das TICs. Para Shark (2014), elas utilizam as tecnologias e sistemas coordenados em áreas chave, com o objetivo de assegurar uma qualidade de vida superior. 
Uma cidade para ser considerada inteligente deve investir nestas tecnologias de alta ponta para melhorar a sua eficiência, impulsionando as TICs como um setor necessário para o desenvolvimento urbano e atraindo talentos humanos especializados para o território, motivados pela melhoria da qualidade de vida. (MCLAREN; AGYEMAN, 2015).

De acordo com a Aenor (2014) este novo modelo de cidade precisa estar fundamentado em três conceitos básicos: tecnologia, sustentabilidade e inovação. $O$ primeiro caso engloba as infraestruturas digitais, as quais permitem que os gestores obtenham uma quantidade de dados suficientemente grandes para auxiliar na gestão eficiente dos recursos e reagir à informação em tempo real. (AENOR, 2014).

Outros autores acreditam que a disponibilidade e qualidade das tecnologias de informação e comunicação não devem definir unicamente uma cidade inteligente. (CARAGLIU; BO; NIJKAMP, 2011). Para Stimmel (2015), a grande questão é que muitas cidades que se consideram inteligentes possuem uma tendência de simplificar a solução dos problemas urbanos utilizando apenas a tecnologia.

As cidades inteligentes precisam ser eficientes, mas também devem preservar a sua espontaneidade e sociabilidade. Elas precisam ser seguras, mas não podem correr o risco de se tornar câmaras de segurança. As cidades não podem perder a sua naturalidade, porque deixariam de ser ricos organismos vivos e se tornariam em algo automático e maçante. Por isso a tecnologia não consegue resolver um problema isoladamente. (TOWNSEND, 2013). Para Townsend (2013), a cidade precisa combinar a tecnologia da informação com a infraestrutura, a arquitetura, os objetos do dia a dia e até com o próprio corpo do cidadão.

De acordo com um estudo conduzido pelo Centre of Regional Science da Vienna University of Technology (2007), as cidades inteligentes não devem focar em um único aspecto. Por isso, eles elencaram seis características para que uma cidade seja integralmente inteligente: a) Economia Inteligente; b) Pessoas Inteligentes; c) Governança Inteligente; d) Mobilidade Inteligente; e) Ambiente Inteligente; e, por fim, f) Vida Inteligente. (VIENNA UNIVERSITY OF TECHNOLOGY. Centre of Regional Science, 2007).

As definições e discussões apresentadas neste tópico conduzem a uma verdade coletiva: para construir uma cidade, as necessidades dos cidadãos devem ser 
consideradas em primeiro lugar. (TOWNSEND, 2013). São os habitantes que irão auxiliar no desenvolvimento de melhores tecnologias para a cidade e, por isso, devem ter um papel imprescindível no combate aos problemas dos centros urbanos. Este é um processo de cocriação com os próprios moradores, que transformam o ambiente urbano de forma inspiradora e racional. (TOWNSEND, 2013; STIMMEL, 2015).

\section{DESTINOS TURÍSTICOS INTELIGENTES}

O debate científico sobre os destinos turísticos inteligentes (DTI) vem crescendo nos últimos anos e a sua conceituação ainda está em progresso. É de comum acordo que a ideia do destino inteligente nasceu da noção de cidade inteligente. (XIANG; TUSSYADIAH; BUHALIS, 2015; LUQUE GIL; ZAYAS FERNÁNDEZ; CARO HERRERO, 2015; BOES; BUHALIS; INVERSINI, 2015; ZHU; ZHANG; LI, 2014).

Apesar disso, o conceito de destino turístico inteligente não deve associar-se exclusivamente ao paradigma das cidades inteligentes, visto que uma série de outras mudanças estruturais no setor turístico justificam a necessidade de novos enfoques na gestão dos destinos. (INVATTUR, 2015).

Tendo isso em vista, Neuhofer, Buhalis e Ladkin (2012) concluíram que as novas tecnologias devem ser entendidas como a principal fonte de inovação, diferenciação estratégica e vantagem competitiva para que a cocriação da experiência nos destinos seja bem-sucedida.

Por outro lado, o termo "inteligente" também pode ser aplicado na própria atividade em si. Então, o turismo inteligente pode ser considerado a progressão do turismo tradicional para uma atividade mais orientada na inovação e no desenvolvimento das tecnologias da informação e comunicação, que dependem de sensores, dados (big data e open data), novos meios de conectividade e troca de informações. (GRETZEL; SIGALA; XIANG; KOO, 2015).

O destino do futuro deverá integrar, estrategicamente e efetivamente, as TICs em toda a sua estrutura, comunicação e interações, cocriando experiências com os turistas em todos os estágios da viagem. (NEUHOFER; BUHALIS; LADKIN, 2012). 
Isto posto, o destino turístico inteligente foi definido por Zhu, Zhang e Li (2014) como uma plataforma de turismo urbana, que integra os recursos turísticos, as TICs (como a Inteligência Artificial, cloud computing e Internet of Things) e as tecnologias móveis inovadoras, fornecendo informações explícitas e serviços eficientes para o turista.

Para Xiang, Tussyadiah e Buhalis (2015), o DTI é um destino construído sob uma base tecnológica que garante o desenvolvimento sustentável do turismo na localidade, além de facilitar a interação do visitante, melhorar a qualidade da experiência do turista e, ainda, aprimorar a qualidade de vida dos residentes.

Por sua vez, Luque Gil, Zayas Fernández e Caro Herrero (2015) acreditam que os destinos turísticos inteligentes não devem ser apenas entendidos pela vertente meramente tecnológica, porque, se assim fosse, eles deveriam ser denominados "destinos turísticos tecnológicos".

Em seu manual de destinos turísticos inteligentes a INVATTUR (2015), por exemplo, elenca seis fatores que justificam a configuração de destinos turísticos em DTI. A inovação tecnológica, indiscutivelmente, configura esta lista, justamente com o comportamento da demanda turística, o surgimento de novos modelos de negócio, o aumento da eficiência, a melhoria da competitividade do destino e o desenvolvimento sustentável.

A SEGITTUR (2015) reconhece a importância da inovação e das tecnologias para a criação dos DTI, mas ela também considera fundamental incluir outros elementos como a sustentabilidade, governança, acessibilidade e os residentes, definindo o destino turístico inteligente como:

[...] um espaço turístico inovador, acessível para todos, consolidado sobre uma infraestrutura tecnológica de vanguarda que garante o desenvolvimento sustentável do território, facilita a interação e a integração do visitante com o entorno e incrementa a qualidade da sua experiência no destino e a qualidade de vida dos residentes. (SEGITTUR, 2015, p. 31, tradução livre).

Ainda que os destinos turísticos inteligentes guardam um inegável paralelismo com as cidades inteligentes, existem algumas diferenças importantes, apresentadas a seguir pela SEGITTUR (2015): a) os limites geográficos do destino podem coincidir ou não com os limites do município; b) no destino turístico o público alvo é o turista; c) o destino inteligente vem impulsionado pelo setor turístico, mas é recomendável que a sua 
governança seja compartilhada com outros atores; d) a interação começa no pré viagem, se estende durante a estadia do turista e continua no pós viagem; e) os DTI estão ligados no incremento da sua competitividade e melhoria da experiência do turista; f) enquanto as cidades inteligentes estão orientadas a melhorar a qualidade de vida dos residentes, os DTI pretendem conseguir um atrativo intrínseco para o visitante (compatível com o bem-estar dos autóctones).

Apesar das particularidades de cada modelo, Luque Gil, Zayas Fernández e Caro Herrero (2015, p. 12, tradução livre) afirmam que "um destino turístico nunca será inteligente se o seu sistema territorial também não for e esta é a finalidade, ao menos de um ponto de vista teórico, das cidades inteligentes.”. Portanto, a diferenciação deve ser mais sutil, levando em consideração os beneficiários das atuações, que na cidade é o residente, e no destino é o turista. (LUQUE GIL; ZAYAS FERNÁNDEZ; CARO HERRERO, 2015).

Com a elucidação do conceito de destino turístico inteligente é importante compreender também o motivo pelo qual um destino consolidado deve se tornar inteligente. Para López de Ávila e García (2013), a principal intenção dessa conversão é revalorizar o destino, permitindo a melhoria da competitividade, o aproveitamento correto dos recursos turísticos, o aumento da eficiência dos processos de produção e comercialização e o uso de fontes de energia renováveis que impulsionem o desenvolvimento sustentável.

Os benefícios em se aplicar projetos e ações para a transformação do destino devem ser observados tanto sob a ótica do visitante, como dos gestores. No primeiro caso, esta nova configuração de destino permite que o turista receba mais informações e serviços convenientes, melhorando a qualidade da sua estadia e, consequentemente, da sua experiência. (ZHU; ZHANG; LI, 2014; LÓPEZ DE ÁVILA; GARCÍA, 2013). Em segundo lugar, o destino inteligente fornece informações e dados ao gestor que facilitam a tomada de decisão, visto que ele acaba por conhecer um pouco melhor o comportamento do turista durante a viagem. (CACHO et al., 2015; ZHU; ZHANG; LI, 2014). 


\section{METODOLOGIA}

A pesquisa inicial que fundamentou este trabalho e que teve por objetivo analisar se Curitiba estava se tornando um destino turístico inteligente, foi classificada quanto aos seus objetivos, procedimentos e natureza. (FILHO; FILHO, 2013). No primeiro caso, ela é uma pesquisa exploratória, porque visou proporcionar maior familiaridade com o tema "destinos turísticos inteligentes", que ainda não estava sendo amplamente estudado na área. (GIL, 2010).

Em relação aos procedimentos, a pesquisa é, primeiramente, bibliográfica, porque trouxe maior entendimento sobre os principais conceitos relacionados ao tema: "destinos turísticos", "cidades inteligentes" e "destinos turísticos inteligentes". (GIL, 2010). Além disso, ela também é documental, porque foram analisados documentos para verificar se os projetos e ações que a cidade Curitiba possuía na área do turismo poderiam enquadrá-la como um destino turístico inteligente. (GIL, 2010).

Por fim, relativamente à natureza, este estudo é qualitativo, porque demonstra o sentido de um determinado fenômeno social, os destinos turísticos inteligentes, e pondera a subjetividade de quem observa, não podendo ser traduzido em números. (FILHO; FILHO, 2013).

A coleta de dados da pesquisa realizada ocorreu em duas etapas: o levantamento bibliográfico e o levantamento documental. Em relação à pesquisa bibliográfica, os materiais foram localizados em bibliotecas, base de dados e sistemas de busca. Após a obtenção da bibliografia, foi feita a leitura e a utilização do material para redigir o marco teórico. (GIL, 2010).

Para a pesquisa documental, o primeiro passo foi identificar as fontes e selecionar os documentos que foram analisados (amostragem): o Plano Diretor de Curitiba (2015), o Plano Municipal de Turismo (2015) e 37 notícias e reportagens publicadas em jornais de importante veiculação estadual e nacional, sites institucionais da Prefeitura, universidades e alguns blogs. Os documentos escolhidos para o levantamento foram coletados durante os meses de agosto e setembro e analisados em setembro de 2016. Com a análise dos conteúdos extraídos desses documentos, foi construído um sistema de categorias e de indicadores. De acordo com Gil (2010) as 
categorias são compostas por um termo chave que indica a significação central do conceito e os indicadores expressam as variações deste conceito.

O sistema de categorias foi desenvolvido de acordo com a metodologia da Sociedad Estatal para la Gestión de la Innovación y las Tecnologías Turísticas (SEGITTUR, 2015). O Ministerio de Industria, Energía y Turismo da Espanha impulsionou em 2012, através do Plano Nacional e Integral de Turismo (2012), uma série de medidas e atuações para transformar o modelo turístico tradicional, e determinou que a SEGITTUR fosse a organização responsável por estabelecer as "linhas gerais de atuação que servem de pauta aos entes gestores dos destinos [...] para dar o passo de converter os seus destinos em destinos turísticos inteligentes.". (SEGITTUR, 2015, p. 62, tradução livre).

A SEGITTUR (2015) elenca quatro eixos fundamentais que o destino turístico maduro deve desenvolver para se tornar um DTI: a inovação, a tecnologia, a sustentabilidade e a acessibilidade. Os projetos e ações de Curitiba que possuíam alguma relação com os conceitos de cidades inteligentes e destinos turísticos inteligentes foram categorizados nos eixos apresentados. No quadro 1 se apresenta os indicadores de cada eixo que foram levados em consideração para designar cada item entre as categorias. Os indicadores também estão baseados no que foi descrito pela SEGITTUR (2015).

QUADRO 1 - CATEGORIAS E INDICADORES DE ANÁLISE DOS DOCUMENTOS

\begin{tabular}{|c|l|}
\hline Categoria & \multicolumn{1}{c|}{ Indicadores } \\
\hline \multirow{3}{*}{ Inovação } & $\begin{array}{l}\text { Troca de conhecimentos; } \\
\text { Desenvolvimento de novos serviços ou produtos melhorados; } \\
\text { Desenvolvimento de novos métodos e processos; } \\
\text { Desenvolvimento de novos modelos de negócio; } \\
\text { Novas formas de organizações públicas e privadas. }\end{array}$ \\
\hline \multirow{5}{*}{ Tecnologia } & $\begin{array}{l}\text { Captação e análise de dados; } \\
\text { Promoção e comunicação online, por meio de site oficial e redes sociais; } \\
\text { Desenvolvimento de dispositivos móveis; } \\
\text { Implementação de Wi-Fi nos espaços públicos; } \\
\\
\text { Open Data; } \\
\text { Automatização de processos; } \\
\text { Soluções que envolvam tecnologia. }\end{array}$ \\
& $\begin{array}{l}\text { Facilitar o acesso da comunidade e turistas a espaços públicos e locais de interesse } \\
\text { turístico; }\end{array}$ \\
& $\begin{array}{l}\text { Facilitar o acesso da comunidade e turistas à informação; } \\
\text { Facilitar o acesso da comunidade e turistas a serviços urbanos e turísticos. }\end{array}$ \\
\hline
\end{tabular}

Continua... 
Continuação.

\begin{tabular}{|l|l|}
\hline Sustentabilidade & $\begin{array}{l}\text { Sustentabilidade ambiental - manutenção dos recursos ambientais; eficiência } \\
\text { energética; coleta e separação de lixo; saneamento; mobilidade urbana; meios de } \\
\text { transporte alternativos; }\end{array}$ \\
$\begin{array}{l}\text { Sustentabilidade sociocultural - cocriação; planejamento participativo; preservação } \\
\text { de aspectos culturais locais; relacionamento entre turista e comunidade autóctone; } \\
\text { Sustentabilidade econômica - distribuição dos benefícios econômicos; promoção e } \\
\text { comercialização de produtos sustentáveis do comércio e artesanato local. }\end{array}$ \\
\hline
\end{tabular}

FONTE: Baseado em SEGITTUR (2015).

Após a leitura integral dos documentos e a seleção das ações, projetos e diretrizes, eles foram categorizados nos quatro eixos estruturais da SEGITTUR (2015).

\section{RESULTADOS E DISCUSSÃO}

Relativamente ao Plano Diretor, foram analisadas as diretrizes propostas na revisão da Lei ${ }^{\circ}$ 14771, publicada em 17 de dezembro de 2015. (CURITIBA. Plano Diretor, 2015). O documento atualizado estava pautado nos três tripés do plano original: Transporte Coletivo, Sistema Viário e Uso do Solo e estabelecia as diretrizes para a política de desenvolvimento urbano, a política ambiental, a política social e econômica e a gestão democrática da cidade. (CURITIBA. Plano Diretor, 2015).

O principal destaque do Plano Diretor (2015) era no eixo da sustentabilidade, em concordância com a imagem de "cidade ecológica" que Curitiba possui. (CURITIBA. Instituto Municipal de Turismo, 2015). É importante salientar que a gestão municipal visava priorizar o transporte público coletivo ao invés do transporte individual e se preocupava em integrá-lo com outros modais, fortalecer a Rede Integrada de Transportes, viabilizar o bilhete único temporal e intermodal e modernizar a sua infraestrutura. (CURITIBA. Plano Diretor, 2015).

Aliado à tecnologia, os órgãos competentes da Prefeitura já utilizavam e queriam aperfeiçoar a obtenção e monitoramento de informações, dados estatísticos e caracterização dos usuários do transporte coletivo para subsidiar o seu processo de planejamento. E em relação à acessibilidade, o plano previa a universalização do acesso ao transporte para as pessoas com deficiência, com dificuldades de locomoção, com necessidades específicas e aos idosos, além de adequação das calçadas e malha viária. (CURITIBA. Plano Diretor, 2015). 
Para López de Ávila e García (2013) algumas propostas de atuação importantes que um destino que quer se tornar inteligente deve implementar na área de mobilidade são, justamente, a gestão eficiente do transporte intermodal; a utilização da tecnologia para a criação de sistemas de gestão do tráfego em tempo real; desenvolvimento de aplicativos com a informação atualizada das rotas do transporte público e do fluxo de passageiros; e a facilitação do acesso aos destinos para que todas as pessoas possam desfrutar dos atrativos turísticos, independente da sua condição física.

Ainda, foi notável o aumento da atenção que se estava dando à inserção da bicicleta no ambiente urbano com, por exemplo, o desenvolvimento do Plano Cicloviário, a melhoria da estrutura cicloviária, implantação do projeto de compartilhamento de bicicletas e ações educativas sobre o uso do modal para incentivar mais cidadãos a utilizá-lo. (CURITIBA. Plano Diretor, 2015). Isto estava em concordância com a metodologia da SEGITTUR (2015) para os destinos inteligentes, pois ela prevê que os gestores municipais devem implementar os transportes alternativos como o aluguel de bicicletas elétricas, instalação de ciclovias e promoção de táxis híbridos ou elétricos, que podem ser utilizados tanto pela comunidade local, como pelo turista.

Por fim, algumas outras diretrizes importantes do Plano Diretor (2015) para transformar Curitiba em uma cidade mais inteligente eram: a) incentivo à cultura empreendedora e à economia criativa, com a formulação do Plano de Inovação e Design, que se relacionavam estreitamente com o eixo da inovação do destino inteligente (SEGITTUR, 2015); e b) a melhoria da gestão democrática da cidade, com a transparência no acesso à informação e dados de interesse público, visto que é papel do governo garantir os dados abertos dos documentos e recursos de informação elaborados pelo setor público, para assim estabelecer a melhoria da gestão dos ativos municipais. (AENOR, 2015).

Seguindo para a análise do Plano Municipal de Turismo (2015), foram verificadas as ações que Curitiba já realizava, retiradas do diagnóstico do cenário vigente, e as ações previstas para as sete áreas estratégicas do plano.

Sobre o cenário então vigente de Curitiba, destacaram-se o eixo da tecnologia e sustentabilidade, devido às ações como, por exemplo, o aplicativo Curta Curitiba; os totens da Prefeitura conectados ao site oficial do IMT; a rede Wi-Fi no Centro 
Histórico; os parques urbanos; bom estado de conservação da rede viária; a ampliação do uso da bicicleta (que também era tratado com prioridade no Plano Diretor); entre outros. (CURITIBA. Instituto Municipal de Turismo, 2015).

Sobre as ações previstas nas áreas estratégicas, o eixo de sustentabilidade, assim como no Plano Diretor (2015), foi o que mais possuiu ações destacadas, levando em consideração a valorização dos bens socioambientais e parques urbanos, mas principalmente o incentivo às produções artísticas e culturais da comunidade, com o incentivo à comercialização de produtos, souvenires e artesanatos locais. (CURITIBA. Instituto Municipal de Turismo, 2015). Este incentivo às produções locais fazia parte da sustentabilidade sociocultural e econômica da SEGITTUR (2015), porque segundo a organização é fundamental desenvolver ferramentas para a manutenção dos aspectos culturais da comunidade local e impulsionar o comércio de produtos sustentáveis como o artesanato tradicional.

No quesito tecnologia, o Plano Municipal de Turismo (2015) previa melhorias na promoção online do destino, com o fortalecimento do site, mídias sociais e o aplicativo Curta Curitiba, além de estímulos para pesquisas, coleta e disseminação de dados e informações do turismo por meio das tecnologias de informação e comunicação, como ocorreu na cidade de Nanjing, China, onde o governo local estava criando um banco de dados para coletar informações sobre os visitantes e assim garantir a qualidade da gestão do turismo, das agências de viagens e dos meios de hospedagem. (WANG; LI; LI, 2013).

A inovação apareceu na cooperação pública e privada em prol do turismo regional; na sensibilização da população para a importância da atividade turística; no estímulo do Sou Curitiba, projeto que fomentava o desenvolvimento de souvenires inovadores; e na criação de regiões gastronômicas. (CURITIBA. Instituto Municipal de Turismo, 2015).

Finalmente, a acessibilidade foi pouco citada no Pano Municipal de Turismo (2015), diferentemente do que foi possível observar no Plano Diretor (2015), o que demonstrava a falta de políticas na área para a atividade turística em específico. Para a SEGITTUR (2015), a acessibilidade é um eixo imprescindível para o destino se tornar inteligente e ela deve estar presente em toda a cadeia de valor do turismo - inclusive no 
acesso à informação e conhecimento pelo consumidor - assegurando a todo e qualquer visitante a liberdade de viajar e realizar a atividade que tenha vontade.

Com a seleção das notícias e reportagens percebeu-se que muitas das ações e projetos que estavam acontecendo em Curitiba possuíam alguma relação com as diretrizes e projetos propostos no Plano Diretor (2015) e no Plano Municipal de Turismo (2015), o que demonstrou a preocupação da gestão municipal em colocar em prática o que foi planejado anteriormente.

Em relação a sustentabilidade, por exemplo, a Prefeitura de Curitiba já havia construído 190 quilômetros de malha cicloviária, além de possuir edital aberto para empresas que quisessem implantar o bike sharing e projetos para permitir o embarque de bicicletas nos ônibus. Outros exemplos sustentáveis foram a implantação das Vias Calmas e Área Calma no centro da cidade (ruas com limite máximo de velocidade em $30 \mathrm{~km} / \mathrm{h}$ e $40 \mathrm{~km} / \mathrm{h}$, respectivamente) e a construção das "calçadas verdes" (ampliações das calçadas tradicionais, pintadas de verde, que servem para estender o espaço de calçada sem a necessidade de obras complexas), que fizeram o número de mortes de pedestres em rua e rodovias diminuir 17\% de 2014 para 2015. (GAZETA DO POVO, 2016a).

O destaque da tecnologia foi a abertura dos dados do transporte para empresas e pesquisadores, facilitando a integração dos itinerários do transporte público com aplicativos, ação que auxiliou a cidade em receber uma menção honrosa no Prêmio Internacional de Transporte Sustentável 2017. (GAZETA DO POVO, 2016b).

Em relação às notícias e reportagens turísticas, Curitiba já possuía o aplicativo Curta Curitiba e a linha de souvenires Sou Curitiba. Levando em conta uma das ações previstas no plano, de elaborar de forma participativa roteiros culturais, foi importante evidenciar os oito novos roteiros turísticos da cidade, lançados em 23 de março de 2016, que cativavam os turistas a conhecer os locais através de modais diferentes como a bicicleta (METRO, 2016), reforçando o eixo da inovação e sustentabilidade na gestão do destino. (SEGITTUR, 2015).

No entanto, considera-se que apesar de possuir projetos e diretrizes relacionados aos DTI e flertar com os conceitos de Smart Cities, Curitiba ainda precisava evoluir em muitos quesitos, como na tecnologia e mobilidade, visto que muitas dessas ações 
estavam previstas para acontecer, ou seja, ainda não estavam sendo implementadas, tornando-se insuficientes para que a cidade se tornasse um destino turístico inteligente.

Deste modo, concluiu-se que Curitiba apresentava potencial para se tornar um destino turístico inteligente, mas ela ainda não o era. A gestão municipal e a população precisariam, primeiramente, começar a perceber Curitiba como um destino turístico, conhecendo e aproveitando os benefícios econômicos, sociais, culturais e ambientais que o turismo bem planejado e executado pode proporcionar para uma localidade.

O primeiro passo a ser dado nesse sentido seria potencializar a promoção e divulgação da cidade, para atrair mais turistas de lazer, além da demanda fixa de negócios e eventos. Conforme apontado por Saraniemi e Kylanen (2011), o destino turístico começa no espaço virtual, e Curitiba deveria aproveitar as tecnologias da informação e comunicação para criar um relacionamento pré e pós viagem com o visitante. Como mencionado anteriormente, o Instituto Municipal de Turismo já possuía um site oficial, com dicas de atrativos, locais para se hospedar e comer, além de um aplicativo para os dispositivos móveis e redes sociais na internet. (CURITIBA. Instituto Municipal de Turismo, 2015). Seria necessário agora que essas tecnologias estejam sempre atualizadas e que cativem o visitante a conhecer o destino antes mesmo de comprar a viagem. (KNOP; MACHADO, 2017).

Estas plataformas, como o site e aplicativos, também auxiliariam na geração de dados online e em tempo real, que poderiam ser utilizados pela gestão pública para monitorar o comportamento do visitante, traçar novas diretrizes e ações para a atividade turística na cidade. (LOPEZ DE ÁVILA; GARCÍA, 2013). Por isso, pesquisas de demanda e de outros dados para o turismo também deveriam ser considerados prioritários na administração da atividade. Eles gerariam informação para o gestor e esta informação geraria conhecimentos para o desenvolvimento e a melhoria do planejamento turístico de Curitiba, além de serem fontes de dados relevantes para provar a importância do turismo para os outros órgãos da Prefeitura e a comunidade local.

Além do mais, para uma cidade ser inteligente os seus gestores devem considerar sempre a educação e as habilidades dos seus habitantes (TOWNSEND, 2013), porque são eles que irão auxiliar no desenvolvimento de melhores tecnologias e empreendimentos para a cidade e, por isso, devem ter um papel imprescindível no 
processo de cocriação do ambiente urbano. Para o turismo vale a mesma premissa. A comunidade local não apenas deve conhecer o mérito da atividade, como também deve se beneficiar das receitas geradas com as viagens e participar ativamente na definição de novas estratégias para o turismo, fazendo com que a sustentabilidade econômica do destino seja alcançada. (SEGITTUR, 2015).

\section{CONSIDERAÇÕES FINAIS}

Neste trabalho, que teve a finalidade de analisar se Curitiba estava se tornando um destino turístico inteligente, se apresentou uma discussão teórica acerca do tema, procedimentos metodológicos para a realização da pesquisa e a análise dos resultados obtidos através do levantamento bibliográfico e documental.

O problema da pesquisa "Curitiba, como uma cidade inteligente, poderia também se tornar um destino turístico inteligente?" foi respondido em partes. Com a pesquisa bibliográfica realizada na revisão teórica, foi possível constatar que sim, se Curitiba fosse uma cidade inteligente, então ela poderia vir a ser um destino inteligente, visto que o destino turístico inteligente surge de uma cidade inteligente. Todavia, as análises documentais do Plano Municipal de Turismo (2015), Plano Diretor (2015), notícias e as reportagens mostraram que Curitiba não era uma cidade inteligente na sua totalidade e ela ainda precisava evoluir em muitos quesitos, como na tecnologia, mobilidade, educação, governança, segurança, entre outros. Nestes documentos até constavam ações, projetos e diretrizes nos quatro eixos dos destinos turísticos inteligentes da SEGITTUR (2015). Porém, nenhum deles foi planejado especificamente com o objetivo de tornar Curitiba em um destino ou cidade inteligente.

Com a pesquisa, outro resultado obtido apresenta-se na definição de um novo conceito para os destinos turísticos inteligentes, desenvolvido pelo autor, com base em todo o material lido e analisado para a redação do marco teórico e da metodologia.

O destino turístico inteligente é o destino turístico maduro que integra as tecnologias da inovação e comunicação (TICs) no desenvolvimento de ações e projetos para o turismo, criando um ambiente turístico inovador, sustentável e acessível para o visitante e o cidadão. 
O destino turístico inteligente nasce de uma cidade inteligente, porque ele também se beneficia do aperfeiçoamento na mobilidade urbana, no trânsito, nas vias públicas, na administração de recursos ambientais, na gestão de dados coletados, entre outros, que a smart city viabiliza. Contudo, uma cidade inteligente não é, necessariamente, um destino turístico inteligente. Para a cidade ser considerada um destino inteligente ela precisa ter, primeiramente, um fluxo turístico relevante que a caracterize como um destino. Ainda, ela deve desenvolver ações tecnológicas exclusivamente para o turismo, visto que a principal diferença entre o DTI e a cidade inteligente é justamente o consumidor final, ou seja, o turista e o residente, respectivamente.

Finalmente, o destino turístico inteligente é ainda um tema recente que carece de definições, de delimitações e estudos. Pode-se afirmar que no Brasil não existem destinos inteligentes, como na Espanha. Por isso, mais pesquisas sobre o tema são imprescindíveis para auxiliar no processo de construção de conhecimento na área, na criação modelos de análise de destinos inteligentes, na identificação de cases de sucesso e na estruturação de destinos inteligentes em todo o mundo, contribuindo para uma atividade turística mais tecnológica, inovadora, acessível e sustentável.

\section{REFERÊNCIAS}

AENOR. El Papel de las Normas en las Ciudades Inteligentes. Madrid, 2014. Relatório. Disponível em: <https://www.esmartcity.es/biblioteca/informe-el-papel-delas-normas-en-las-ciudades-inteligentes>. Acesso em: 17/09/2017.

AENOR. Las Normas para las Ciudades Inteligentes. Madrid, 2015. Relatório. Disponível em:

<http://www.agendadigital.gob.es/planes-actuaciones/Bibliotecaciudadesinteligentes/M aterial\%20complementario/normas_ciudades_inteligentes.pdf $>$. Acesso em: 04/03/2018.

BASTOS H. Z. L. Análise de desempenho e projeto de uma infraestrutura de cidade inteligente para transporte público de Curitiba. $89 \mathrm{f}$. Dissertação (Mestrado em Informática) - Setor de Ciências Exatas, Universidade Federal do Paraná, Curitiba, 2015. Disponível em: <http://acervodigital.ufpr.br/handle/1884/40987>. Acesso em: 17/09/2017. 
BOES, K.; BUHALIS, D.; INVERSINI, A. Conceptualising Smart Tourism Destination Dimensions. In: TUSSYADIAH, I.; INVERSINI, A. Information and Communication Technologies in Tourism 2015. Lugano: Springer International Publishing Switzerland, 2015. p. 391-403. Disponível em:

<http://www.academia.edu/10985742/Boes_K._Buhalis_D._and_Inversini_A._2015_C onceptualising_Smart_Tourism_Destination_Dimensions_in_Tussyadiah_I._and_Invers ini_A._eds_ENTER_2015_Proceedings_Lugano_Springer-

Verlag_Wien_ISBN_9783319143422_pp._391-404>. Acesso em: 17/09/2017.

CACHO, A.; ESTAREGUE, D.; FIGUEREDO, M.; LUCAS, J.; AURÉLIO, M.; FARIAS, H.; KAREN, L.; CÂMARA, P.; CACHO, N.; LOPES, F.; MENDES FILHO, L.; ALVES, C. A Smart Destination Initiative: the Case of a 2014 FIFA World Cup Host City. In: IEEE INTERNATIONAL SMART CITIES CONFERENCE, 2015, Guadalajara. Proceedings... Guadalajara: IEEE, 2015. p. 1-6. Disponível em: <http://ieeexplore.ieee.org/document/7366223/>. Acesso em: 17/09/2017.

CARAGLIU, A.; DEL BO, C.; NIJKAMP, P. Smart cities in Europe. Journal of Urban Technology, v. 18, n. 2, p. 65-82, 2011. Disponível em: <http://intaaivn.org/images/cc/Urbanism/background\%20documents/01_03_Nijkamp.pdf>. Acesso em $17 / 09 / 2017$.

COOPER, C.; FLETCHER, J.; WANHILL, S.; GILBERT, D.; SHEPHERD, R. Turismo: princípios e práticas. 2. ed. Porto Alegre: Bookman, 2001.

CURITIBA. Instituto Municipal de Turismo. Plano Municipal de Turismo 2015-2017. Curitiba, 2015. Disponível em:

<http://multimidia.turismo.curitiba.pr.gov.br/2015/11/pdf/00000817.pdf>. Acesso em: $17 / 09 / 2017$.

CURITIBA. Lei ${ }^{\circ} 14771$, de 17 de dezembro de 2015. Dispõe sobre a revisão do Plano Diretor de Curitiba de acordo com o disposto no art. 40, $\S 3^{\circ}$, do Estatuto da Cidade, para orientação e controle do desenvolvimento integrado do Município. Diário Oficial Eletrônico, Curitiba, PR, n. 236, 17 dez. 2015. Disponível em: <http://www.ippuc.org.br/visualizar.php?doc=http://admsite2013.ippuc.org.br/arquivos/ documentos/D310/D310_001_BR.pdf>. Acesso em: 17/09/2017.

FILHO, M. C. F.; FILHO, E. J. M. A. Planejamento da pesquisa científica. 1. ed. São Paulo: Atlas, 2013.

GAZETA DO POVO. Cai drasticamente o número de mortes no trânsito de Curitiba. 2016a. Disponível em: <http://www.gazetadopovo.com.br/vida-e-cidadania/caidrasticamente-o-numero-de-mortes-no-transito-de-curitiba9ytd12xd12h7jr9x0me2mnd78>. Acesso em: 04/03/2018.

GAZETA DO POVO. Curitiba recebe menção honrosa em prêmio de transporte sustentável. 2016b. Disponível em: <http://www.gazetadopovo.com.br/vida-ecidadania/futuro-das-cidades/curitiba-recebe-mencao-honrosa-em-premio-de-transporte- 
sustentavel-exmjnxsk4114uqbtip8jdd8ot?utm_source=facebook\&utm_medium=midiasocial\&utm_campaign=midia-social $>$. Acesso em: 04/03/2018.

GIL, A. C. Como elaborar projetos de pesquisa. 5. ed. São Paulo: Atlas. 2010.

GRETZEL, U.; SIGALA, M.; XIANG, Z; KOO, C. Smart tourism: foundations and developments. Electronic Markets, v. 25, n. 3, p. 179-188, 2015. Disponível em: $<$ https://www.researchgate.net/publication/280719315_Smart_tourism_foundations_and _developments>. Acesso em: 17/09/2017.

INVATTUR. Destinos turísticos inteligentes: manual operativo para la configuración de destinos turísticos inteligentes. Valencia, 2015. Relatório. Disponível em: $<$ http://www.thinktur.org/media/Manual-de-destinos-tur\%C3\%ADsticosinteligentes.pdf>. Acesso em: 17/09/2017.

KNOP, M. F. T.; MACHADO, J. S. Cibercultura e as influências das redes sociais virtuais na escolha de destinos turísticos: direcionamentos a partir de teorias sociológicas dos laços sociais. Turismo e Sociedade, v. 10, n. 2, p. 1-20, 2017. Disponível em: <http://revistas.ufpr.br/turismo/article/view/52528/32575>. Acesso em: 04/03/2018.

LOPEZ DE ÁVILA M., A.; GARCÍA S., S. Destinos turísticos inteligentes. Harvard Deusto Business Review, v. 224, p. 58-66, 2013. Disponível em: <https://dialnet.unirioja.es/servlet/articulo?codigo=4248506>. Acesso em: 17/09/2017.

LOTZ, E. G. Destinos turísticos: discursos sobre fatores determinantes de atratividade. 113 f. Dissertação (Mestrado em Turismo e Hotelaria) - Universidade do Vale do Itajaí, Balneário Camboriú, 2002.

LUQUE GIL, A. M.; ZAYAS FERNÁNDEZ, B.; CARO HERRERO, J. L. Los Destinos Turísticos Inteligentes en el marco de la Inteligencia Territorial: conflictos y oportunidades. Investigaciones Turísticas, v. 10, p. 1-25, 2015. Disponível em: $<$ https://rua.ua.es/dspace/bitstream/10045/52102/1/Investigaciones_Turisticas_10_01.pd f>. Acesso em: 17/09/2017.

MCLAREN, D.; AGYEMAN, J. Sharing Cities: A Case for Truly Smart and Sustainable Cities. Cambridge: The MIT Press, 2015.

METRO. Conheça oito roteiros turísticos para conhecer Curitiba. 2016. Disponível em: $<$ https://www.metrojornal.com.br/plus/2016/03/30/conheca-oito-roteiros-turisticosconhecer-curitiba.html>. Acesso em: 04/03/2018.

MOLETTA, V. F.; GARCIA, R. K. O. Comercializando um destino turístico. 1. ed. Porto Alegre: SEBRAE/RS, 2000.

MTUR; SEBRAE; FGV. Índice de Competitividade do Turismo Nacional: Curitiba. Brasília, 2015. Disponível em: 
<http://www.turismo.gov.br/sites/default/turismo/o_ministerio/publicacoes/Indice_com petitividade/2015/Curitiba_RA_2015.pdf>. Acesso em: 17/09/2017.

NEUHOFER, B.; BUHALIS, D.; LADKIN, A. Conceptualising technology enhanced destination experiences. Journal of Destination Marketing \& Management, v. 1, n. 1-2, p. 36-46, 2012. Disponível em:

<http://www.sciencedirect.com/science/article/pii/S2212571X12000091>. Acesso em: 17/09/2017.

OLIVEIRA, D. Curitiba e o mito da cidade modelo. 1. ed. Curitiba: Editora UFPR, 2000.

RUIZ, T. C. D. A dinâmica evolutiva da competitividade do destino turístico Curitiba. 354 f. Tese (Doutorado em Geografia) - Setor de Ciências da Terra, Universidade Federal do Paraná, Curitiba, 2015. Disponível em: <http://acervodigital.ufpr.br/handle/1884/41771>. Acesso em: 17/09/2017.

SANTOS, J. C. V. Região e destino turístico: sujeitos sensibilizados na geografia dos lugares. São Paulo: All Print, 2013.

SARANIEMI, S.; KYLANEN, M. Problematizing the concept of tourism destination: An analysis of different theoretical approaches. Journal of Travel Research. v. 50, n. 2, p.133-143, 2011. Disponível em:

<http://journals.sagepub.com/doi/pdf/10.1177/0047287510362775>. Acesso em:

17/09/2017.

SEGITTUR. Informe destinos turísticos inteligentes: construyendo el futuro. Madrid, 2015. Relatório. Disponível em:

<http://www.segittur.es/opencms/export/sites/segitur/.content/galerias/descargas/docum entos/Libro-Destinos-Inteligentes-en-Espaol.pdf>. Acesso em: 17/09/2017.

SHARK, A. R. What makes smart cities smart? In: SHARK, A. R.; TOPOTKOFF, S.; LÉVY, S. Smarter Cities for a Bright Sustainable Future: A Global Perspective. Alexandria: Public Technology Institute, 2014. p. 1-9.

STIMMEL, C. L. Building smart cities: analytics, ICT and design thinking. Boca Raton: Auerbach Publications, 2015.

THOMAZ, G. M. Processo de mineração de conteúdo em mídias sociais para auxílio na gestão de destinos turísticos. 223 f. Dissertação (Mestrado em Turismo) Setor de Ciências Humanas, Universidade Federal do Paraná, Curitiba, 2014. Disponível em: <http://acervodigital.ufpr.br/handle/1884/37396>. Acesso em: 17/09/2017.

TOWNSEND, A. M. Smart cities: big data, civic hackers and the quest for a new utopia. New York: W. W. Norton \& Company, 2013. 
VALLS, J. F. Gestão integral de destinos turísticos sustentáveis. 1. ed. Rio de Janeiro: Editora FGV, 2006.

VIENNA UNIVERSITY OF TECHNOLOGY. Centre of Regional Science. Smart cities: ranking of European medium-sized cities. Viena, 2007. Relatório. Disponível em: <http://www.smart-cities.eu/download/smart_cities_final_report.pdf >. Acesso em: $17 / 09 / 2017$.

VIGNATI, F. Gestão de destinos turísticos: como atrair pessoas para polos, cidades e países. 1. ed. Rio de Janeiro: Ed. Senac Rio, 2008.

XIANG, Z.; TUSSYADIAH, I.; BUHALIS, D. Smart destinations: Foundations, analytics and applications. Journal of Destination Marketing \& Management, v. 4, n. 3, p. 143-144, 2015. Disponível em:

<http://www.sciencedirect.com/science/article/pii/S2212571X15000360>. Acesso em: $17 / 09 / 2017$.

WANG, D.; LI, X.; LI, Y. China's "smart tourism destination" initiative: a taste of the service-dominant logic. Journal of Destination Marketing \& Management, v. 2, n. 2, p. 59-61, 2013. Disponível em:

<https://www.sciencedirect.com/science/article/pii/S2212571X13000231>. Acesso em: 04/03/2018.

ZHU W.; ZHANG L.; LI, N. Challenges, Function Changing of Government and Enterprises in Chinese Smart Tourism. e-Review of Tourism Research, v. 5, p. 1-4, 2014. Disponível em: <http://agrilife.org/ertr/files/2014/02/enter2014_RN_75.pdf>. Acesso em: 17/09/2017.

Recebido em: 17-09-2017.

Aprovado em: 17-10-2017. 